Gestão e Desenvolvimento, 22 (2014), 31-54

\title{
PROJETO DE CRIAÇÃO DA “ROTA DO GRANITO” NO ÂMBITO DA LIGA DOS AMIGOS DE ALPEDRINHA
}

\section{Marília Miguel Hilário* Pedro Carvalho ${ }^{\dagger}$}

\begin{abstract}
Resumo: Ouve-se falar constantemente nas dificuldades das Associações Sem Fins Lucrativos para cumprirem a sua missão devido às dificuldades que se fazem sentir. Este tipo de associações debate-se diariamente com este problema, mas para o resolver é necessário desenvolver as associações e criar projetos úteis que aproveitem o seu potencial e o do meio envolvente.

Este estudo visa apresentar uma proposta de um projeto que permita revitalizar uma associação sem fins lucrativos, a Liga dos Amigos de Alpedrinha, e perspetivar-lhe um futuro através da colaboração com outras entidades e pessoas para que todos possam beneficiar de um projeto comum. $O$ projeto proposto, uma rota turística, utiliza os recursos da associação e da vila de Alpedrinha para criar uma estratégia que vai ao encontro do que o PENT define como um dos produtos turísticos em que Portugal deve apostar, Touring Cultural e Paisagístico.

A Rota do Granito tem como principal objetivo promover $e$ desenvolver a Liga dos Amigos de Alpedrinha e todas as entidades envolvidas, para que em conjunto possam assegurar o seu futuro. Pretende-se ainda que o projeto possibilite o aumento do número de artesãos e das vendas de artesanato, para que as gerações vindouras possam manter uma ligação mais estreita com as suas origens $e$ beneficiem de um projeto delineado para aproveitar os recursos existentes, mas de forma a assegurar a sua conservação.
\end{abstract}

Palavras-chave: Rota Turística, Turismo Cultural, Serra da Gardunha, Projetos de Rotas

\footnotetext{
* Mestre em Gestão de Empresas, Escola Superior de Gestão do Instituto Politécnico de Castelo Branco.

† Docente na Escola Superior de Gestão do Instituto Politécnico de Castelo Branco. Email: pedro.manuel81@gmail.com
} 


\title{
PROJECT FOR CREATION OF "THE ROUTE OF GRANITE" UNDER THE LEAGUE OF FRIENDS OF ALPEDRINHA
}

\begin{abstract}
One constantly hears about the difficulties that Nonprofit Associations have in order to fulfil their mission because of the problems that are felt. These types of associations struggle with this problem daily, yet to solve it, it is necessary to develop the associations and to create useful projects that make the most of its potential and of the surrounding environment.

This study aims to present a proposal to revitalize the League of Friends of Alpedrinha and promote its future through the collaboration with other organizations and individuals so that all may benefit from a common project. The proposed project, a tourist route, uses the resources of the association and the village of Alpedrinha to create a measurement which meets what PENT defines as one of the tourism products in which Portugal must venture, Cultural and Landscape Touring.

The principal objective of this "Granite Route" is to promote and develop the League of Friends of Alpedrinha and all concerned entities so that together they can secure their future. It is also expected that the project will facilitate the increase of the number of artisans and craft sales, so that future generations can maintain a closer bond with their origins and benefit from a project designed to take advantage of the existing resources, but also to ensure its preservation.
\end{abstract}

Keywords: Tourist Route, Cultural Tourism, Serra da Gardunha, Projects Routes

\section{INTRODUÇÃO}

Nos últimos anos a crise assumiu o lugar de destaque nas conversas, nas notícias e estende-se um pouco por todo o lado, pelas empresas privadas e públicas, pelas famílias e pelo associativismo. Mas, nas associações a crise vai muito mais além da crise económica. Nessas entidades a crise económica é cada vez maior, mas também o é a crise de sócios, de apoio moral, de compreensão, de dedicação, de recursos materiais e humanos. As associações sem fins lucrativos sobrevivem devido à teimosia de uns e à determinação de outros e dependem do apoio de todos. Evitar o fim das associações sem fins lucrativos não depende apenas dos órgãos sociais, depende de todos, porque este tipo de associação é um registo do passado, da história e da cultura, mas não significa que se deva manter no passado. Urge encontrar soluções para que as associações sem fins lucrativos avancem e não dependam da caridade dos que as rodeiam, soluções que permitam que o trabalho investido pelos voluntários que delas fazem parte possa gerar receitas e que também possam aproveitar o potencial endógeno da zona que as 
envolve. Sem soluções que protejam e desenvolvam estas associações e que as transformem em associações autossuficientes, corre-se o risco de elas desaparecerem provocando uma nova crise, uma crise de identidade cultural, já que esta é protegida e divulgada pelas associações sem fins lucrativos de caráter cultural.

A solução não pode ser geral, pois cada associação tem o seu próprio potencial e a sua envolvente, cada caso tem de ser analisado individualmente. É desta forma que surge o presente estudo, como forma de delinear uma proposta para este problema e em particular para a Liga dos Amigos de Alpedrinha (LAA).

Outrora estas associações eram apoiadas pelas entidades governamentais e infelizmente muitas habituaram-se a essa inércia de "esperar pelos subsídios". A realidade mudou e o país está numa situação muito difícil e quando isso acontece os primeiros a sentir os cortes são estas associações. Torna-se assim necessário acompanhar os tempos e criar formas para que as associações possam financiar as suas próprias atividades e desenvolver projetos que ajudem as populações locais. $\mathrm{O}$ futuro do associativismo depende da sua capacidade para se modernizar e adaptar às novas necessidades, resumindo depende da sua capacidade para se desenvolver (IDS 2001). Para Artur Martins (2009) a longevidade do associativismo sem fins lucrativos deve assentar em dois vetores: nos seus fundamentos (a razão pela qual foi criada e existe) e nos valores.

Para a Liga dos Amigos de Alpedrinha, o que aqui se propõe, é criar uma rota turística que aproveite as potencialidades da própria associação, nomeadamente o Museu Etnográfico e a Casa-Museu da Música que retratam a história e as tradições desta região e a forte ligação de Alpedrinha com a música e a sua evolução ao longo dos anos.

\section{O TERCEIRO SETOR}

O art. $^{\circ} 82$ da Constituição da República Portuguesa (CRP) define os três setores de propriedade dos meios de produção, sendo o primeiro o setor público que pertence ao Estado e a outras entidades públicas, o segundo o setor privado e o terceiro o setor cooperativo e social onde se inserem as associações e organizações coletivas sem fins lucrativos. A OCDE (2003) define o terceiro setor como um setor entre o Estado e o mercado, promotor de missões económicas e sociais, que prosseguem o interesse público e cujo objetivo final não é a distribuição de lucro. $\mathrm{O}$ facto do terceiro setor não ter como objetivo principal o lucro não significa que não possa desenvolver atividades lucrativas, como referem Andrade e Franco (2007), se a organização passar por uma escassez de fundos, ou tiver um desejo de autonomização, pode optar por desenvolver 
atividades lucrativas em paralelo com atividades não lucrativas relacionadas com a missão. Para estes autores o importante é que os fundos conseguidos com as atividades lucrativas sejam aplicados para suportar os custos das atividades não lucrativas, mantendo assim como prioridade a missão da organização.

Devido à capacidade para mobilizar doações e trabalho voluntário, o que permite oferecer preços mais baixos, o terceiro setor mostra-se provavelmente mais eficiente que o setor público ou o privado (OCDE, 2000). Segundo Carvalho (s. d.) o futuro passará pelo terceiro setor que tem cada vez maior peso nas economias, pois há uma crescente procura de bens e serviços fornecidos por entidades que não pertencem aos setores lucrativo e público, pelo que estas entidades irão ter um contributo importante na criação de emprego e na distribuição do rendimento.

\subsection{O Associativismo}

A associação é definida por Camacho (1994, p. 61) como uma "Reunião de várias pessoas para um fim em comum". Segundo esta definição o ser humano associa-se desde a sua existência. Contudo, a palavra em si começa a tomar importância na Europa por volta do século XIX. Goodolphim (1876) defende que o Homem não consegue satisfazer as suas necessidades sozinho, pelo que se deve associar com outros que partilhem os seus interesses. Defensor dos operários, o autor, acredita que a associação entre eles é a única forma de satisfazer as suas necessidades, pois não podem contar com mais ninguém.

Coelho (2010) também fala nas associações de caráter profissional que são referenciadas no Evangelho de S. Lucas, mas defende um associativismo muito mais abrangente, não relacionado apenas com o ser humano trabalhador, mas também com o ser humano social. $\mathrm{O}$ autor acredita que o associativismo no ser humano é um renunciar a atitudes egoístas e solitárias para construir um homem solidário e tribal, mais Humano, porque o Homem é um ser social e o associativismo é inerente a ele. Para o Instituto para o Desenvolvimento Social (2001) o associativismo é a expressão organizada da sociedade civil, já que apela à responsabilização e intervenção dos cidadãos em várias esferas da vida social e constitui um meio importante de exercer a cidadania. O associativismo deve reger-se pelos princípios da Liberdade, da Democracia "um associado, um voto" e da solidariedade (IDS, 2001).

A Declaração Universal dos Direitos Humanos (1948) refere no

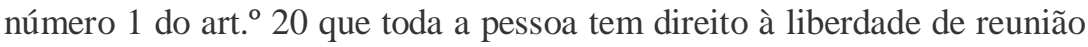
e de associação pacíficas. Portugal reforça esse direito na CRP, no

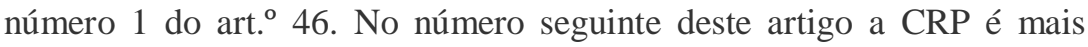
específica e estabelece a liberdade das associações para prosseguirem os 
seus fins sem que as autoridades públicas interfiram e sem que possam ser dissolvidas pelo Estado. Em Portugal o associativismo teve a sua origem a partir do séc. XII com instituições ligadas à Igreja com utilidade caritativa para apoio de doentes, pobres, viúvas e órfãos. No séc. XIX surge outro tipo de associativismo relacionado principalmente com o mundo laboral e de forma a defender os direitos dos operários, Goodolphim (1876). Influenciada pela Revolução Industrial em Inglaterra e pela Revolução Francesa que apregoava os ideais "Liberdade, Igualdade e Fraternidade", surgiu em Portugal a Revolução Liberal e as populações começaram a organizar-se para tentar reduzir a crise e as dificuldades que enfrentavam (Coelho, 2010), objetivos que lhes eram comuns. Foram, assim, surgindo muitas associações ligadas às profissões, como forma de os operários se ajudarem entre si e outras ligadas à Assistência Social que apoiavam os enfermos e os idosos. As associações de tipo cultural surgiram associadas aos movimentos operários no séc. XIX, mas dedicaram-se à atividade cultural relacionada com o teatro e a música, como é o caso (Artur Martins, 2009) das bandas de música.

De acordo com Augusto Flor (2009) o associativismo foi evoluindo ao longo do tempo quanto à forma de organização, funcionamento e resposta às necessidades das populações de modo a encontrar soluções para os problemas que individualmente as pessoas não conseguiam resolver. Desta forma o associativismo acabou por resolver funções do Estado que não quiseram, não puderam ou não souberam resolver. Para o Professor Doutor Raul Iturra (2009) sem o associativismo não existiria Cultura, Recreio e Desporto em Portugal.

Também Coelho (2010) vê o trabalho voluntário e economicamente desinteressado praticado nas associações como um fator essencial de desenvolvimento que complementa a ação do Estado e estabelece com ela uma parceria dinâmica. Para este autor o associativismo é particularmente favorável ao exercício da democracia, constituindo por isso um importante fator de construção de nova cidadania e definição de identidade local, e de grupo, para a integração social e expansão cultural, e para a integração social e expressão cultural no exterior do sistema economicista dominante.

Para Viegas (1986) as associações culturais populares materializam espaços privilegiados de uso e transformação dos códigos e símbolos gerados nas condições materiais de existência das diversas camadas populares.

Infelizmente, de acordo com o Instituto Português da Juventude (2005), os jovens portugueses são os que menos participam nas organizações associativas a nível europeu. Também Ferreira (2008) num 
estudo que realizou para aferir a relação do associativismo com a cultura cívica dos jovens portugueses verificou que apenas um em cada quatro dos jovens entrevistados se identificou com a atividade associativa, em especial com a desportiva que é a que mobiliza um conjunto maior de jovens. Contudo, o autor encontrou um sentido de responsabilidade coletiva mais consolidado e uma maior consciência de dever nos jovens associados, o que faz com que se sintam mais responsáveis pela melhoria da sociedade e mais empenhados no trabalho voluntário comunitário.

\subsection{Associações Sem Fins Lucrativos}

Carvalho (s. d.) define organização privada sem fins lucrativos como uma entidade de iniciativa privada, que fornece bens, serviços e ideias para melhorar a qualidade de vida em sociedade, onde poderá existir trabalho voluntário, e que não remunera os detentores e fornecedores de capital. O autor concorda com Drucker (1992) em que qualquer Organização Sem Fins Lucrativos (OSFL) existe para conseguir provocar mudanças nas pessoas e na sociedade.

Leitão et al. (2009) reconhecem a importância das associações de cultura, recreio e desporto afirmando que a ação que desenvolvem junto das populações locais constitui um património nacional específico de valor social incalculável. Este "património nacional" assume ainda maior importância (de acordo com os mesmos autores) porque na maior parte das vezes o trabalho associativo realiza-se no contexto de múltiplos constrangimentos, como a falta de recursos materiais e humanos e recursos financeiros suficientes e da necessidade de um quadro de apoio institucional mais apropriado à realidade associativa do país.

Em 2006, de acordo com o INE, I.P (2011) existiam 45.543 Instituições sem fins lucrativos, das quais aproximadamente $50 \%$ exerciam atividades nas áreas da cultura e recreio e $13,7 \%$ nos serviços sociais. Em 2010 (INE, I. P., 2012) as OSFL representaram 2,8\% do $\mathrm{VAB}$ e $5,5 \%$ dos postos remunerados, revelando uma ascensão deste setor na economia portuguesa. De acordo com o mesmo organismo as instituições das áreas da cultura e do recreio, apesar de serem a maioria, têm maior dificuldade em gerar rendimentos. Segundo um estudo realizado por Ornelas et al. (2013) existem 30.122 Associações de Cultura, Recreio e Desporto, localizando-se 1.010 no distrito de Castelo Branco.

No setor lucrativo as necessidades pessoais e organizacionais de sobrevivência passam por um crescimento económico-financeiro que aumente os lucros, no setor não lucrativo as necessidades pessoais e/ou sociais que não possam ser satisfeitas pelo setor lucrativo passam pela sobrevivência da organização e pela sustentabilidade das suas atividades 
(Carvalho, S. d.). Para ambos os casos a forma de conseguir alcançar os objetivos, de acordo com Carvalho (s. d.) é pesquisar, criar, produzir e oferecer bens, serviços e ideias com valor para os clientes, de forma a alterar os comportamentos e a estabelecer soluções transacionais sustentadas.

\section{TURISMO}

De acordo com a OMT o turismo é "um conjunto de atividades desenvolvidas pelas pessoas durante as viagens em locais situados fora do seu ambiente habitual por um período consecutivo que não ultrapasse um ano, por motivos de lazer, de negócios e outros."

A Organização Mundial de Comércio (OMC) ${ }^{\star}$ considera o turismo importante, nomeadamente pela sua contribuição para o emprego e como fonte de rendimento. Para esta organização, o setor do turismo é um dos mais dinâmicos da economia, faz uso intensivo da mão-de-obra e mantém importantes vínculos com outros setores da economia. Para a OMC uma das caraterísticas fundamentais do turismo internacional é o movimento transfronteiriço de consumidores, o que permite que até os trabalhadores não qualificados de zonas mais afastadas sejam exportadores de serviços, como por exemplo vendendo artesanato.

Leeuwen e Nijkamp (2011) afirmam que o turismo se transformou num setor independente devido ao bem-estar da sociedade no qual o rendimento e o descanso assumiram um lugar importante nas decisões económicas das pessoas. Também o comportamento dos turistas mudou radicalmente, passando de um único período de férias para vários períodos de férias com uma duração mais curta e maiores distâncias. De acordo com as Communautés Européennes (2003) começou a surgir um turismo alternativo às clássicas férias nas praias ensolaradas e a ter um crescimento mais rápido que qualquer outro tipo de turismo. Este turismo alternativo deve-se, de acordo com o mesmo organismo, à mudança dos gostos dos turistas e até devido à conjuntura económica, optando, assim, os turistas por saídas mais curtas e mais frequentes ao longo do ano, férias mais ativas e maior interesse com a envolvente ambiental. As Communautés Européennes (2003) defendem que o turismo traz vantagens como: novas possibilidades de emprego, diversidade e estabilidade da economia local, fonte de receitas suplementares, alteração do nível de vida local e conservação do património natural e cultural local. Ruschmann (2008) refere como vantagens a valorização do

\footnotetext{
$\$$ http://www.wto.org
} 
artesanato, da herança cultural e do património histórico e o orgulho étnico.

\subsection{O Turismo em Portugal}

De acordo com informação disponibilizada pelo Turismo de Portugal, I. P. (2007) $83 \%$ das visitas em Portugal têm quatro motivações primárias: Sol e Mar 37,8\%, Touring Cultural e Paisagístico 29,7\%, Turismo de Natureza 8,2\% e City break 7,6\%. Dos turistas da Região Centro, 66\% são atraídos pelo Turismo Cultural e Paisagístico e dos turistas que se deslocam a Portugal devido a este tipo de turismo, 24,3\% são espanhóis, o que faz com que Espanha seja o principal emissor deste tipo de turistas.

De acordo com o Turismo de Portugal, I. P. (2007), os turistas definem o conceito de férias como "Diversão e Descanso associado à descoberta de novos locais e interação com a cultura local". Para este organismo a Região Centro deve apostar no Touring Cultural e Paisagístico, pois é o que mais turistas atrai devido às caraterísticas da região. O Turismo de Natureza atrai $8,2 \%$ dos turistas no país, o que representa 5,4\% dos turistas da Região Centro.

Os circuitos turísticos religiosos e culturais e o turismo de natureza são duas das linhas de atuação destacadas na revisão do PENT para 20132015 (DR, 2013). Para os circuitos religiosos e culturais são propostas a estruturação de rotas e de itinerários experienciais baseados em temas âncora da identidade portuguesa e dos fatores distintivos que caraterizam o país e promovem a sua declinação regional.

\subsection{Turismo Cultural e de Natureza}

Para Smith (1989, referido em Cunha, 2001) o Turismo Cultural inclui os centros culturais, os grandes museus, grandes monumentos religiosos (catedrais, mesquitas, templos budistas), os locais onde se desenvolveram no passado as grandes civilizações do mundo, os grandes centros de peregrinação, o pitoresco ou «cor local» ou a cultura camponesa que constituem as preferências dos turistas. Para Leeuwen e Nijkamp (2011) a herança cultural é um ativo firme para qualquer destino turístico e menos sujeito à sazonalidade causada pelo tempo e pelo clima. Uma significativa parte da história cultural do mundo está retratada nas relíquias construídas pelo homem no passado que têm um valor social nobre e único a que muitas vezes se chama herança cultural. Este é um conceito amplo que não inclui apenas castelos, museus ou igrejas, mas também valores mais complexos como paisagens históricas e outros. Também o Turismo de Portugal, I. P. (2012) considera que o turismo é, cada vez mais, um 
importante fator dinamizador da preservação, fruição e valorização do património cultural e artístico de Portugal. De entre os diversos elementos patrimoniais, os museus e monumentos são vetores essenciais da oferta turístico-cultural, contribuindo para a diferenciação dos destinos e para o desenvolvimento de novas oportunidades de negócio turístico. O Turismo Cultural assume-se como um produto estratégico que fomenta a fruição do património cultural, mas, também, gera outputs económicos relevantes para os diferentes agentes da cadeia de valor da atividade turística.

Para Cunha (2001), a Cultura sempre foi um dos mais importantes fatores de desenvolvimento do turismo e tem vindo a acentuar-se cada vez mais. De acordo com o autor grande parte das viagens realizam-se para destinos que dispõem de fatores culturais notáveis, como por exemplo os locais históricos, monumentos, centros arqueológicos, centros de peregrinação, concentrações de caráter étnico e muitos outros. Os museus representam assim, para o autor, uma forma de criar artificialmente alguns dos fatores culturais.

O Turismo de Natureza, para Graburn (1998, referido por Cunha, 2001), manifesta-se de duas maneiras diferentes: o turismo ambiental e o turismo ecológico. $\mathrm{O}$ ambiental relaciona-se com os vários aspetos da terra, do mar e do céu e com o seu estado de pureza; por sua vez, o turismo ecológico ou ecoturismo inclui as viagens para as áreas naturais com o fim de observar e compreender a natureza e a história natural do ambiente tendo o cuidado de manter inalterável a integridade do ecossistema (Ecoturism Society). A motivação dominante reside no desejo de «regresso à natureza», na contemplação do meio natural e na evasão ao meio urbano. Os visitantes apreciam atravessar as montanhas e as florestas e observar as relações entre as pessoas e a terra.

Para Ruschmann (2008) a interação entre turismo e natureza é incontestável pois a natureza constitui a matéria-prima da atividade. Devido à deterioração dos meios urbanos, as pessoas procuram cada vez mais nas suas férias e fins de semana regiões com belezas naturais, mas é fundamental analisar os possíveis efeitos negativos deste tipo de turismo e criar condições para os evitar, Ruschmann (2008). Para o autor é muito importante um turismo organizado e bem pensado, para que os turistas e o turismo de natureza não afetem a própria natureza. Este tipo de turismo carateriza-se pelo envolvimento físico dos seus participantes durante a viagem e divide-se em hard (com participação intensa) e soft (com participação leve, sem grandes desgastes físicos).

Uma das atividades que se pode incluir no Turismo de Natureza é o pedestrianismo ou caminhada. Para a Federação de Campismo e 
Montanhismo de Portugal (FCMP) o pedestrianismo é uma atividade desportiva, turística e ambiental na qual se percorrem percursos pedestres a pé ao longo de caminhos e trilhos de preferência tradicionais ou históricos, na natureza ou em meio urbano que não envolve grandes dificuldades técnicas. Para a Federação os percursos interpretativos ou culturais permitem a observação privilegiada do meio em que a geologia, a geomorfologia, a fauna, a flora, a história, a arqueologia, a arquitetura e $\mathrm{o}$ artesanato constituem possibilidades inúmeras. A prática desta atividade pode ser realizada em percursos pedestres não sinalizados no terreno ou em itinerários balizados, como as rotas.

\subsection{Rota Turística}

Gómez e Quijano (1992) definem itinerário como a descrição de um caminho ou rota em que são especificados os lugares de passagem e onde é proposto um conjunto de atividades e serviços durante a sua realização. Para os autores a rota é um itinerário cujo ponto de partida e de chegada não coincidem, pelo que este conceito está associado a uma direção, a um percurso dirigido.

Para Chan (2005) a rota tem como função a promoção de uma área, de uma região ou de uma temática com potencial turístico. As suas principais caraterísticas são facilitar o encontro do visitante com o meio e a sensação de liberdade que proporciona ao visitante para se movimentar num determinado destino. As rotas podem apresentar-se em dois formatos, trilhos ou passeios temáticos, dependendo se se desenrolam em espaços urbanos ou rurais e podem abordar temáticas culturais ou naturais.

As rotas pretendem guiar as atividades destacando o que merece a pena conhecer do novo território e constituem um produto idóneo e frequentemente utilizado para a promoção de espaços concretos (Ramírez, 2011). Para o autor as rotas convidam o visitante a recorrer um percurso no qual predomina uma determinada categoria patrimonial, podendo ser manifestações culturais, testemunhos do passado arqueológico ou histórico, património artístico, industrial ou espaços naturais. Marques e Santos (2010) acreditam que através do turismo, as localidades rurais podem tornar-se competitivas e procurar novos mercados através do desenvolvimento sustentável dos seus produtos e serviços. Estes autores defendem que as localidades rurais têm capacidade para agregar ao seu negócio atividades não-agrícolas como o Turismo, o que faz com que elas se integrem, cresçam e se desenvolvam. As rotas turísticas surgem muitas vezes como solução ao nível do turismo para o desenvolvimento sustentável das populações rurais, utilizando como estratégia os recursos endógenos de modo a minimizar a 
dependência dos elementos externos (Marques e Santos, 2010). Desta forma as rotas turísticas podem ser uma forma de dinamizar a economia das zonas rurais, recorrendo ao seu potencial endógeno e desenvolvendo um turismo sustentável que protege os recursos naturais por não representar um turismo de massas.

\section{LIGA DOS AMIGOS DE ALPEDRINHA}

A Liga dos Amigos de Alpedrinha é uma associação sem fins lucrativos de caráter cultural e recreativo fundada no dia 1 de outubro de 1950 com o objetivo de fomentar "o progresso e desenvolvimento de Alpedrinha quer no aspeto material quer espiritual". Ou seja, a associação foi criada para zelar, de um modo geral pelos interesses de Alpedrinha e dos alpetrinienses. Em 1981 foi publicada a sua constituição formal no Diário da República de 20 de abril, III Série, $n^{o}$ 91, onde constam como fins da associação: o reforço dos laços entre os habitantes de Alpedrinha e as comunidades alpetrinienses existentes em Portugal e no estrangeiro; a promoção cultural, recreativa e desportiva, visando a divulgação, progresso e desenvolvimento de Alpedrinha. Foi distinguida pela Câmara Municipal do Fundão com a Medalha de Mérito do Concelho em 1993 pelo seu trabalho na divulgação da cultura e da promoção da Vila.

Atualmente tem como missão criar laços entre as comunidades alpetrinienses existentes em todo o mundo e fazer Alpedrinha progredir através do desenvolvimentos cultural. A sua missão é realizada através dos eventos culturais como concertos, encontros de poetas; das suas atividades como concursos de desenho, literatura e convívios; das várias secções, nomeadamente o Museu Etnográfico, a Casa da Música António Osório de Sá, a Biblioteca Dr. Santos Costa, a Escola de Música e o Jornal "Informação".

Como a maioria das associações culturais os seus recursos financeiros são insuficientes e derivam das quotas dos associados, subsídios, donativos e da realização de atividades para angariação de fundos. Com a diminuição dos subsídios ao longo dos últimos anos, como se pode observar no Gráfico I, torna-se urgente encontrar outras formas de conseguir os fundos monetários necessários à concretização da sua missão. 


\subsection{Envolvente da LAA}

A Liga dos Amigos de Alpedrinha situa-se na vila de Alpedrinha que pertence ao concelho do Fundão e distrito de Castelo Branco, na zona Centro do país. De acordo com o Programa Operacional Regional do Centro (2007-2013) a Região Centro integra um espaço que incorpora um vasto e diversificado património natural de reconhecida qualidade paisagística e ambiental. Esta região possui ainda as heranças históricoculturais de diferentes tempos e civilizações (Lusitana, Romana, Visigoda e Árabe) patentes no património histórico e arquitetónico espalhado pelo território. Eusébio (2006) considera que é consensual o facto da Região Centro de Portugal ter um grande potencial para se transformar num destino turístico a nível nacional. Os fatores como a diversidade e a riqueza das atrações turísticas, a localização geográfica, as boas acessibilidades, a hospitalidade dos residentes, os preços competitivos e o clima de segurança são algumas das razões que a autora aponta para evidenciar o elevado potencial que a região apresenta em termos turísticos.

Gráfico I

Representação dos Subsídios na Receita Total da LAA

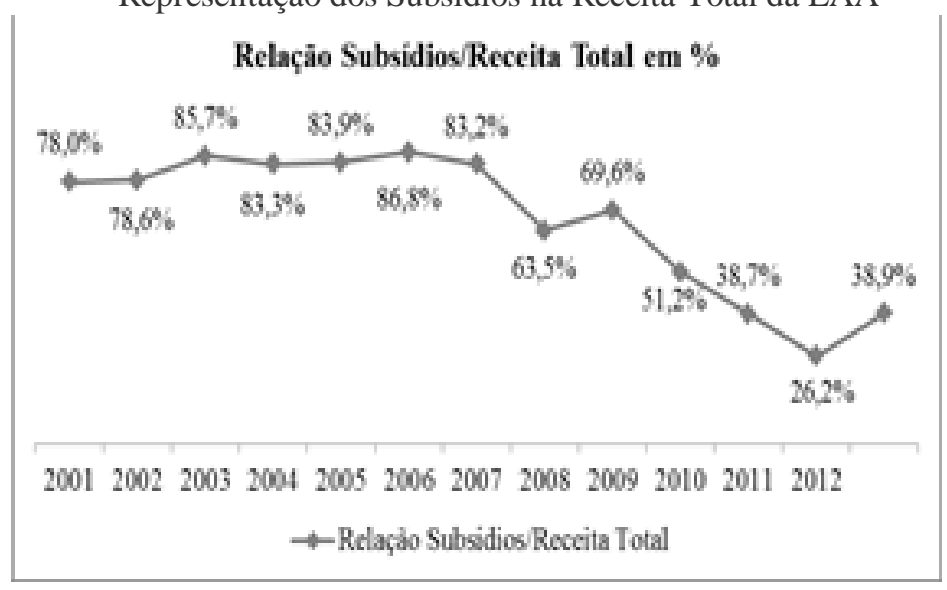

Fonte: Elaboração Própria

A vila de Alpedrinha remonta aos romanos, está situada a 556 metros de altitudes e foi sede de concelho entre 1675 e 1855 , tem $18,22 \mathrm{~km}^{2}$ de área e de acordo com o INE, I. P. 1.087 habitantes. A vila engloba um vasto património cultural (monumental, artístico, etnográfico) e natural (Serra da Gardunha). É a típica vila da Beira Baixa com casario de granito, tradições e cultura bem enraizadas como se pode observar nos 
quatro museus propriedade de entidades privadas. Além do património a vila tem vários recursos turísticos como atividades, eventos, gastronomia, transportes, acessibilidades e desportivos. De entre os vários atrativos podem destacar-se a Serra da Gardunha, Calçada Romana, Palácio do Picadeiro, Igreja Matriz, Chafariz D. João V, Casa da Câmara, Casa da Comenda, entre outros.

A Serra da Gardunha é um "braço" da Serra da Estrela com aproximadamente $20 \mathrm{Km}$ de comprimento e 1.224 metros de altura e é dominada pelo granito. A serra é rica em beleza natural e possui atrativos únicos, como a planta endémica Asphodelus bento-rainhae (lado norte) e curiosos como as formações rochosas. Nesta serra é ainda possível apreciar uma grande variedade de espécies animais e vegetais.

Apesar dos atrativos existentes, Alpedrinha não atrai um número de visitantes satisfatório durante o ano. A Câmara Municipal do Fundão tem em funcionamento três Centros do Visitante no concelho, o da Aldeia Histórica de Castelo Novo, o do Palácio do Picadeiro em Alpedrinha e o da Moagem-Cidade do Engenho e da Arte no Fundão. Como se pode observar no Gráfico II, a aldeia histórica de Castelo Novo recebe um volume de visitantes muito maior que os outros dois centros, atingindo no ano de 2012 cerca de 12.000 visitantes, enquanto que Alpedrinha recebeu cerca de 3.000 visitanes. Tendo em conta que estas localidades se encontram a $7 \mathrm{Km}$ de distância, ambas nas encostas da Gardunha e que têm caraterísticas comuns, como o tipo de construções e o material utilizado, o passado histórico, o património arquitetónico, esta diferença é abismal. Este facto pode dever-se a que Castelo Novo beneficiou de divulgação e campanhas de marketing incluídas no programa das Aldeias Históricas durante vários anos, pelo que nesse espaço de tempo foi criada uma imagem forte que atrai os visitantes. Alpedrinha apesar do património e do espólio museológico tem um número inferior de visitantes. Os museus pertencem a entidades privadas sem fins lucrativos que não têm meios para promocionar o espólio nem para manter as portas abertas ao público diariamente. 


\section{Gráfico II}

Número de visitantes dos últimos 3 anos por Centro de Visitante

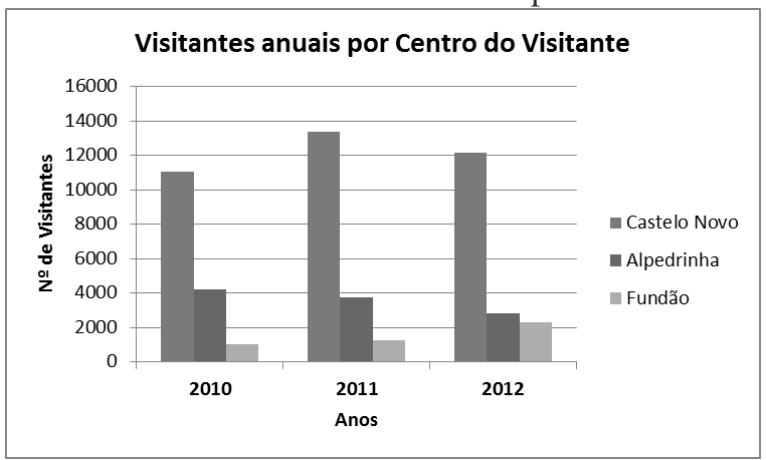

Fonte: Elaboração Própria a partir de dados da Fundão Turismo, E. M.

\section{ROTA DO GRANITO}

A cultura é um dos grandes atrativos da vila de Alpedrinha devido a vários fatores: pela quantidade de monumentos, pelos museus, pelo artesanato típico, pela conservação dos eventos e tradições religiosas, pela gastronomia típica e pela preservação dos usos e costumes.

De acordo com o Turismo de Portugal, I. P. (2007), independentemente da motivação primária, $50 \%$ dos turistas executam atividades de lazer relacionadas com Passeios Pedestres, Experiências Gastronómicas e visitas a Monumentos e dos visitantes da Região Centro 66,2\% são atraídos pelo Touring Cultural e Paisagístico.

O que se propõe neste estudo é a criação de uma rota turística no âmbito da Liga dos Amigos de Alpedrinha que possa vir a ajudar a associação a ser autossuficiente economicamente, aproveitando os seus recursos, nomeadamente os dois museus. O Museu Etnográfico está instalado no $2^{\circ}$ andar da sede da associação, foi criado em 1984 e retrata a vida das gerações passadas através de objetos de uso diário, utensílios de profissões e até roupas e chapéus. A Casa da Música António Osório de Sá era a casa da Família Osório de Sá, conhecida a nível nacional pelos seus dotes musicais. No seu espólio encontram-se grande parte dos instrumentos das antigas bandas filarmónicas de Alpedrinha, várias partituras para bandas filarmónicas escritas pelo Padre Parente e partituras da Família Osório de Sá. A casa encontra-se em requalificação para incorporar a Sala de Exposições das Bandas Filarmónicas, a Sala de Exposição das partituras, a Sala da Família Osório, a Sala da Música da LAA, a Sala de Exposições anuais, a Sala da Música Popular do concelho e da região e a Sala de Exposições temporárias, a Sala para eventos e a Loja de artesanato. 
Apesar do vasto espólio que os museus contêm é necessário compreender que não vão atrair um número significativo de visitantes isoladamente, mas se este projeto for desenvolvido em conjunto com as restantes entidades detentoras de museus na vila e for incluído o património natural (Serra da Gardunha) e a aldeia histórica, a rota pode vir a ser um sucesso. Para que as OSFL de Alpedrinha sobrevivam e possam realizar os objetivos para que foram criadas é necessário que elas próprias colaborem entre si, criando uma estratégia comum.

A criação duma rota turística no âmbito da LAA pretende aproveitar o potencial endógeno da envolvente e criar uma parceria estreita com as outras entidades que possuem museus.

O nome escolhido para a rota é Rota do Granito, porque é a rocha predominante na Serra da Gardunha e as freguesias de Castelo Novo e de Alpedrinha têm a maioria das suas casas construídas em granito, incluindo os edifícios que acolhem os museus que vão ser incluídos na rota. Pretende-se que a Rota do Granito seja uma viagem pela história e tradição desta zona ao longo dum caminho rodeado de granito. Os principais objetivos para a sua criação são: incentivar a proteção do património natural, histórico e cultural; dar maior notoriedade à LAA, à vila e às entidades envolvidas; gerar receitas para cumprir a missão da associação e as obras necessárias para melhorar a rota; promover o artesanato local e incentivar os artesãos a produzi-lo; dar aos artesãos a possibilidade de expor e vender o seu artesanato num local fixo dentro da Rota do Granito; incrementar o comércio no circuito da rota.

A Rota do Granito é definida como uma Pequena Rota (percurso inferior a $30 \mathrm{Km}$ ) com um percurso linear que começa na aldeia histórica de Castelo Novo com a visita ao Núcleo Museológico, continua subindo o troço de Calçada Romana junto à ribeira de Alpreada e atravessa a Serra da Gardunha. O percurso passa junto às antenas da R.T.P. (Rádio Televisão Portuguesa), cujo terreno pertence à Freguesia de Alcongosta e segue até à Portela (separação entre Alcongosta e Alpedrinha) descendo em direção à vila de Alpedrinha pela Calçada Romana até ao Palácio do Picadeiro para visitar o Centro de Interpretação da Transumância propriedade da CMF, após a visita desce-se o último troço de Calçada Romana e segue-se em direção à Igreja Matriz para visitar o Museu de Arte Sacra da Paróquia de Alpedrinha. O museu seguinte da rota é a Casa da Música, propriedade da Liga dos Amigos de Alpedrinha e logo em seguida o Museu Etnográfico que pertence à mesma associação. A rota termina com a visita ao Museu dos Embutidos da Santa Casa da Misericórdia de Alpedrinha. Durante o percurso pela vila de Alpedrinha é possível apreciar o património histórico e as curiosidades que fazem da 
zona histórica em si um museu, como as janelas manuelinas, as casas senhoriais, as casas típicas com as varandas de madeira, as janelas decoradas com rendas, entre outros. Na figura I é apresentada a ficha técnica da rota onde constam várias informações úteis para a sua realização, como a descrição, algumas informações técnicas, cuidados especiais a ter e normas de conduta, contactos da LAA e uma imagem satélite do percurso. Pretende-se que a ficha técnica ajude a conhecer melhor a rota para que exista uma preparação prévia adequada.

Tendo em conta que os principais tipos de turismo que a zona Centro atrai são o Turismo Cultural e Paisagístico (66,2\% do total nacional), o Turismo de Sol e mar (11,5\% do total nacional) e o Turismo de Natureza (5,4\% do total nacional [Turismo de Portugal, I. P. (2007)] a Rota do Granito, com a componente cultural e de natureza, adequa-se ao tipo de turista que se desloca para esta região. De acordo com o mesmo organismo em Portugal as principais atividades de lazer praticadas pelos turistas são: passeios pedestres $51 \%$, experiência gastronómica 50,9\%, visita a monumentos $48,9 \%$ e visita a parques naturais $39,6 \%$; numa percentagem mais baixa encontram-se as viagens/excursões de conhecimento a pontos da região/país com 23,7\%. A nível de nacionalidades, o Turismo de Portugal, I. P. (2007) conclui que a maior percentagem de turistas estrangeiros na zona Centro vem de Espanha e França com $10,8 \%$, seguidos pela Itália com $8,4 \%$ dos turistas. Pode-se então definir o público-alvo da Rota do Granito de acordo com o Quadro I.

Quadro I

Público-alvo definido para a Rota do Granito

\begin{tabular}{|c|c|c|c|c|}
\hline \multirow{6}{*}{ 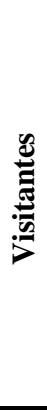 } & \multicolumn{4}{|c|}{ Público-alvo Rota do Granito } \\
\hline & Faixa etária & $25-44$ & \multicolumn{2}{|c|}{$45-65$} \\
\hline & Interesses & Cultura & Natureza & $\begin{array}{c}\text { Preocupações } \\
\text { ecológicas }\end{array}$ \\
\hline & Especificidades & $\begin{array}{c}\text { Ornitologia } * \\
\text { Outros animais }\end{array}$ & \multicolumn{2}{|c|}{$\begin{array}{l}\text { Formações rochosas } \\
\text { Flora }\end{array}$} \\
\hline & Tipologia & Grupos & Particulares & $\begin{array}{l}\text { Agências de } \\
\text { viagens }\end{array}$ \\
\hline & $\begin{array}{c}\text { Época } \\
\text { preferencial das } \\
\text { férias }\end{array}$ & \multicolumn{3}{|c|}{ Fora da época alta } \\
\hline
\end{tabular}

* Parte da Zoologia relativa às aves.

Fonte: Elaboração Própria

Esta definição do público-alvo para a rota foi realizada tendo em conta a faixa etária das pessoas que realizam este tipo de atividades e os atrativos oferecidos ao longo do percurso. 


\section{Figura I}

\section{Ficha Técnica da Rota do Granito}

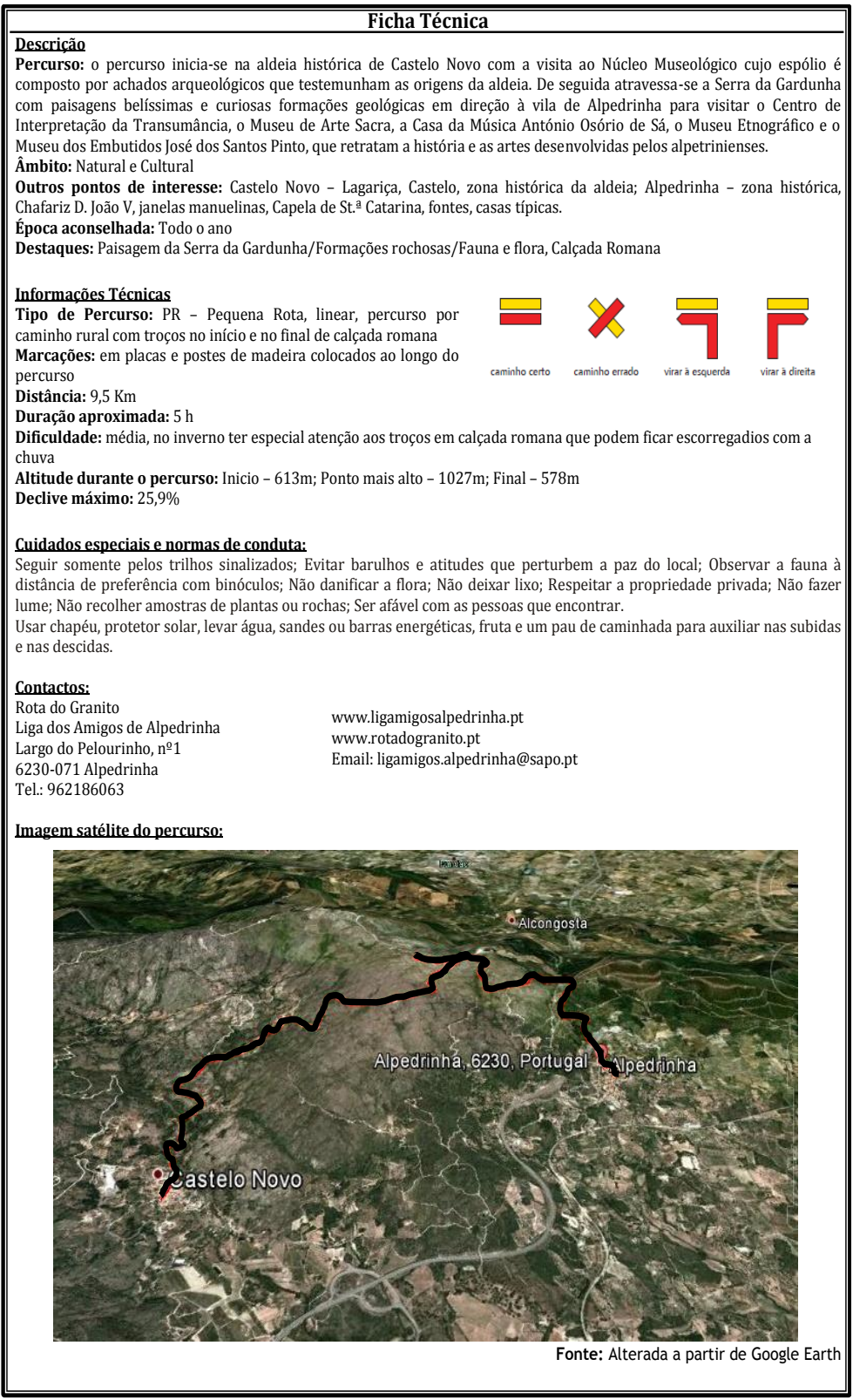




\subsection{Os Parceiros}

Van Deth (1997, citado por Viegas, 2004, pp. 33-34) afirma que as associações voluntárias induzem efeitos positivos, quer a nível macrosocial, quer micro-social. No primeiro caso, pelo seu papel de intermediação social, propiciando a integração sistémica entre o indivíduo e o estado ou entre os diferentes grupos do todo social. A nível microsocial, as associações voluntárias desenvolvem competências específicas e redes sociais, que, em conjunto, favorecem as condições para que os indivíduos atinjam os seus objectivos.

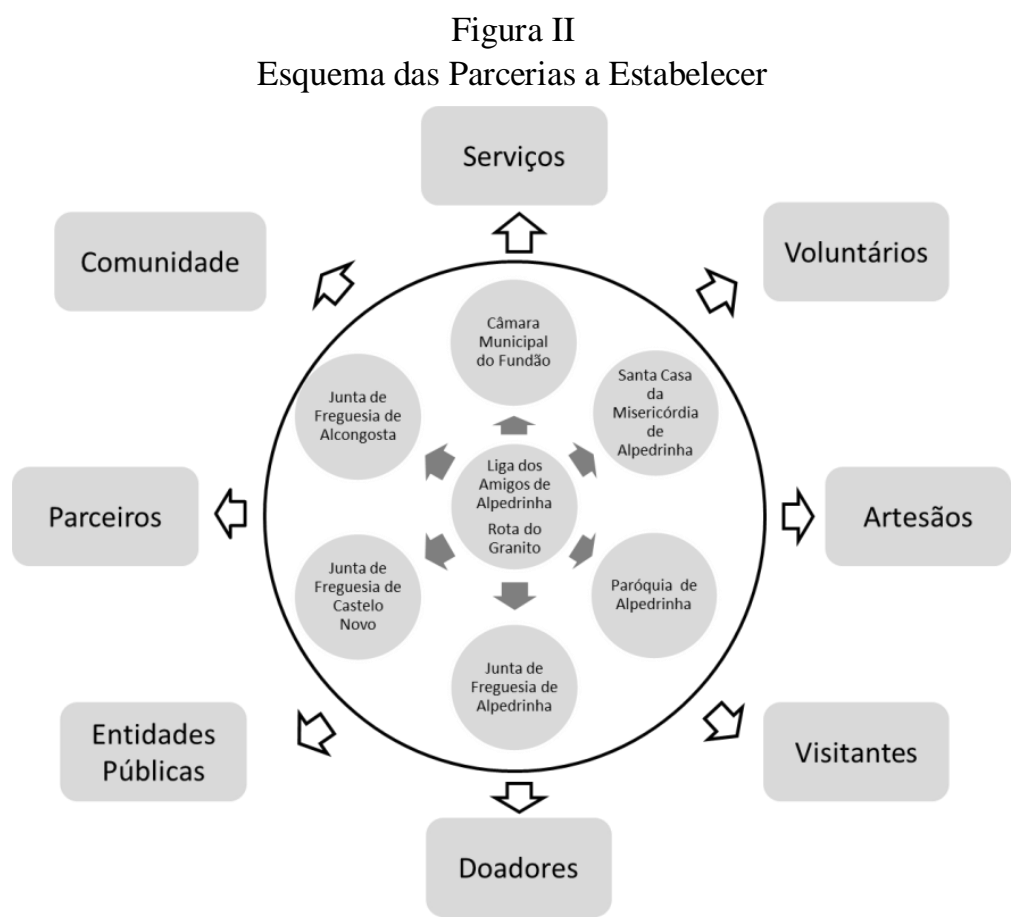

O que se pretende é que a Liga dos Amigos de Alpedrinha crie uma relação de estreita colaboração com vários stakeholders/parceiros (Figura II) para que em conjunto possam fazer com que a Rota do Granito cumpra os objetivos pretendidos.

Os parceiros que a LAA deve envolver no projeto da Rota do Granito são:

- Santa Casa da Misericórdia de Alpedrinha - proprietária do Museu dos Embutidos José dos Santos Pinto. O embutido é um trabalho muito 
minucioso e consiste em combinar pequenos fragmentos de madeira de diferentes tipos de árvores, aproveitando as suas cores naturais para conseguir criar motivos ornamentais. A técnica de embutir madeira tornou-se uma verdadeira arte nas mãos José Parente Pinto que enviou para todo o país magníficos móveis de embutido com desenhos que ele próprio concebia. À Alpedrinha doou este magnífico museu que testemunha a grandeza desta arte.

- Paróquia de Alpedrinha - proprietária do Museu de Arte Sacra que possui peças de caráter religioso com centenas de anos.

- Câmara Municipal do Fundão - proprietária do Núcleo Museológico de Castelo Novo que expõe várias peças recuperadas nas escavações arqueológicas realizadas na aldeia e que testemunham a história da mesma. É proprietária do Palácio do Picadeiro que alberga o Centro de Interpretação da Transumância que tem como objetivo principal dar a conhecer aos visitantes um pouco do mundo da transumância de uma forma dinâmica e moderna.

- Juntas de Freguesia de Alpedrinha, Alcongosta e Castelo Novo às quais pertence o caminho que será utilizado na rota.

Para que a rota possa ser bem sucedida será necessário criar relações com outras entidades e pessoas, nomeadamente artesãos, voluntários, comunidade, entidades públicas, doadores, visitantes, proprietários de serviços de alojamento e restauração e outras que possam ser benéficas.

\section{CONSIDERAÇÕES E RECOMENDAÇÕES FINAIS}

A situação difícil em que se encontra a Liga dos Amigos de Alpedrinha e que é igual à situação da maioria das associações culturais e recreativas deriva da inércia que se foi instalando quando as condições melhoraram e os subsídios começaram a ser atribuídos. Durante algumas décadas em que os subsídios do Município do Fundão e outras entidades pagavam mais de $80 \%$ das despesas da associação aconteceu o que acontece nas empresas quando a procura é grande, não se investe. A responsabilidade desta situação não se pode atribuir aos sucessivos dirigentes, porque foram fazendo o que sabiam e podiam. A responsabilidade é talvez da mentalidade que se tem vindo a instalar nos portugueses em geral. Passar-se de uma época em que a pessoa trabalhadora "pouco valia" e tinha de lutar para conseguir sobreviver, para uma época em que as ajudas vinham de vários locais e eram outros os que decidiam, fez com que se instalasse uma mentalidade de comodismo nas pessoas e as associações são dirigidas por pessoas. Os subsídios chegavam certos todos os meses, as despesas eram pagas e com 
o passar do tempo as coisas mudaram, os subsídios reduziram e as associações têm de procurar soluções, as atividades não se podem resumir a atividades culturais e recreativas, têm de existir outras que as financiem e é assim que surge este estudo, para apresentar uma solução prática.

Pode, então, concluir-se que a Liga dos Amigos de Alpedrinha possui potencial para se tornar mais autónoma a nível financeiro. Mas, para que este possa ser um projeto sustentável a associação não pode trabalhar sozinha, tem de trabalhar em conjunto com entidades que também têm potencial e também precisam de apoio. Em conjunto podem aproveitar o potencial turístico existente na envolvente e criarem uma estratégia conjunta que as torne independentes da "boa vontade" das entidades públicas.

A Rota do Granito pode diferenciar-se de todas as rotas que têm sido implementadas no concelho pelo seu caráter inovador, pois pretende ser um projeto que parte do potencial de duas localidades e de várias entidades, conseguindo que trabalhem unidas para conseguirem ultrapassar as suas dificuldades em conjunto. Da mesma forma que se pretende aproveitar o potencial natural da Serra da Gardunha como ponte para criar uma união entre a aldeia histórica de Castelo Novo e a vila de Alpedrinha, pretende-se que esta rota seja a ponte que vai unir todas as entidades detentoras dos museus da vila, os artesãos, os serviços existentes e possibilitar que a longo prazo se possam revitalizar os serviços turísticos que agora se encontram encerrados.

Este é um projeto que pode vir a alcançar bons resultados porque aproveita o potencial endógeno da zona para desenvolver uma atividade turística que beneficia da crise que vive o país. Com a crise que se instalou em Portugal as pessoas têm de alterar os seus hábitos nas férias e optam cada vez mais pelo interior, é mais económico e mais genuíno. Bem implementado este projeto pode vir a alcançar bons resultados no futuro. Para que se possa beneficiar de uma melhoria continuada e não perder o interesse dos visitantes é importante que todo o processo, desde as reuniões com as entidades parceiras, à implementação da rota e ao seu desenvolvimento, seja alvo de avaliações contínuas para detetar possíveis falhas e proceder às correções necessárias. A avaliação também vai possibilitar a adequação da rota à procura e a inclusão, no futuro, de eventos culturais e até de outras localidades que também se encontram nas encostas da Gardunha. 


\section{BIBLIOGRAFIA}

Andrade, A. \& FRANCO, R. (2007), Economia do Conhecimento: Organizações sem Fins Lucrativos (1-58), Porto: SPI - Sociedade Portuguesa de Inovação.

Camacho, A. (1994), O Nosso Dicionário, Lisboa: Didáctica Editora.

Carvalho, J. (s. d.), $O$ Desempenho nas Organizações sem Fins Lucrativos. Consultado em 12 de fevereiro de 2013 em, http://www.ismai.pt/NR/rdonlyres/ODesempenhonasOrgani548eww pbdemdeqhfasmdqksyxxgzwkbshtlj.pdf.

Chan, N. (2005), "Circuitos Turísticos - Programación y Cotización", $3^{\text {a }}$ ed. Coleção Temas de Turismo, Argentina: Ediciones Turísticas de Mario Banchik.

Coelho, V. (2010), "O Associativismo em Portugal - Estratégias de Desempenho", Associação Portuguesa de Portadores de Pacemakers e CDI's, \#12, 12-17.

Communautés Européennes. (2003), Le Patrimoine naturel et culturel au service d'un développement touristique durable dans les destinations touristiques non traditionnelles, Luxemburgo: Office des publications officielles des Communautés européennes.

Constituição da República Portuguesa de 1976. (1976), VII Revisão Constitucional 2005. Consultado em 18 de outubro de 2012 em http://www.parlamento.pt/Legislacao/Documents/constpt2005.pdf.

Cunha, L. (2001), Introdução ao Turismo, Lisboa : Verbo

Declaração Universal dos Direitos Humanos. (1948), Consultado em 18 de outubro de $2012 \mathrm{em} \mathrm{http://dre.pt/util/pdfs/files/dudh.pdf.}$

Diário da República de 20 de abril de 1981, III Série, No 91, P. 5142. (1981), Publicação que certifica a escritura pública da constituição da Liga dos Amigos de Alpedrinha.

Diário da República de 16 de abril de $201311^{a}{ }^{a}$ série, n. ${ }^{\circ}$ 74, PP. 2171 2202. (2013), Plano Estratégico Nacional do Turismo - Revisão do plano de desenvolvimento do turismo no horizonte de 2015. Consultado em 2 de maio de 2013 em http://www.turismodeportugal.pt/Portugu\%C3\%AAs/turismodeportu gal/destaque/Documents/PENT_RCM\%2024_2013_16\%20abril.pdf. Drucker, P. (1992), Administração de Organizações sem Fins Lucrativos - Princípios e Práticas (N. Montingelli Jr, Trad.), São Paulo: Pioneira Thomson, (Obra original publicada em 1989). 
Eusébio, M. (2006), Avaliação do impacte económico do turismo a nível regional - $O$ caso da Região Centro de Portugal, Tese de Doutoramento em Turismo (Apoiada financeiramente pelo Instituto de Turismo de Portugal), Universidade de Aveiro, Aveiro, Portugal.

Ferreira, P. (2008), "Associações e Democracia - Faz o Associativismo alguma diferença na cultura cívica dos jovens portugueses?" Sociologia, Problemas e práticas, $\mathrm{n}^{\circ}$ 57, 109-130. Consultado em 11 de fevereiro de 2013 em http://www.scielo.oces.mctes.pt/scielo.php?pid=S087365292008000200006\&script=sci_abstract.

Flor, A. (2009), "Prefácio", In S. Leitão, G. Ramos, \& A. Silva, Colectividades de Cultura, Recreio e Desporto: Uma caracterização do associativismo confederado em Portugal, Confederação Portuguesa das Colectividades de Cultura, Recreio e Desporto, Lisboa.

Gómez, J. \& Quijano, C. (1992), Rutas e Itinerarios turísticos en España, Madrid: Editorial Síntesis.

Goodolphim, C. (1876), A Associação: História e Desenvolvimento das Associações Portuguezas, Lisboa: Typographia Universal.

INE, I. P. (2011), Conta Satélite das Instituições sem fim lucrativo em 2006. Consultado em 20 de março de 2012 em, http://www.ine.pt/xportal/xmain?xpid=INE\&xpgid=ine_destaqu es\&DESTAQUESdest_boui $=122548251 \& D E S T A Q U E S m o d o=2$.

INE, I. P. (2012), Conta Satélite da Economia Social 2010 Resultados Preliminares. Consultado em 2 de janeiro de 2013 em, $\mathrm{http}: / / \mathrm{www}$. ine.pt/xportal/xmain?xpid=INE\&xpgid=ine_destaques\& DESTAQUESdest_boui $=150318107 \& D E S T A Q U E S m o d o=2$.

Instituto para o Desenvolvimento Social. (2001), Guia para o Associativismo, Lisboa: Autor.

Instituto Português da Juventude. (2005), Colóquio sobre o Associativismo, Jornal URBI et Orbi, $\mathrm{n}^{\circ}$ 267/15.

Iturra, R. (2009), Colectividades, In S. Leitão, G. Ramos, \& A. Silva, Colectividades de Cultura, Recreio e Desporto: Uma caracterização do associativismo confederado em Portugal, Confederação Portuguesa das Colectividades de Cultura, Recreio e Desporto, Lisboa.

Leeuwen, E. \& Nijkamp, P. (2011), Operational advances in tourism research, [Research Memorandum 2011-19] Faculty of Economics and Business Administration, Amsterdam. 
Leitão, S., Ramos, G. \& Silva, A. (2009), Colectividades de Cultura, Recreio e Desporto: Uma caracterização do associativismo confederado em Portugal, Confederação Portuguesa das Colectividades de Cultura, Recreio e Desporto, Lisboa.

Marques, C. \& Santos, C. (2010). Capital Social como fator de desenvolvimento em rotas turísticas, Gaia Sciencia, 4(1), 21-34.

Martins, A. (2009), As colectividades de Cultura, Recreio e Desporto como parte integrante e significativa do $3^{\circ}$ sector, In S. Leitão, G. Ramos, \& A. Silva, Colectividades de Cultura, Recreio e Desporto: Uma caracterização do associativismo confederado em Portugal, Confederação Portuguesa das Colectividades de Cultura, Recreio e Desporto, Lisboa.

OCDE. (2000), Social Enterprises, Editions OCDE. Consultado em 10 de fevereiro de 2013 em http://www.keepeek.com/Digital-AssetManagement/oecd/urban-rural-and-regional-development/socialenterprises_9789264182332-en.

OCDE. (2003). The Non-profit Sector in a Changing Economy, Editions OCDE.

Ornelas, J., Duarte, T., Seixas, T., Jerónimo, J., Martins, A., Matos, C., Nunes, D., Varela, F. \& Costa, L. (2013), Liderança Comunitária Estudo Colaborativo com Dirigentes Associativos, Almada: Tipografia Lobão, Lda.

Ramírez, J. (2011), "Los caminos del patrimonio. Rutas turísticas e itinerarios culturales", Pasos - Revista de Turismo y Patrimonio Cultural, Vol. 9, $\mathrm{n}^{\mathrm{o}}$ 2, pp. 225-236. Consultado em 5 de janeiro de 2013 em http://www.pasosonline.org/Publicados/9211/PS0211_01.pdf.

Ruschmann, D. (2008), Turismo e planejamento sustentável: a proteção do meio ambiente ( $14^{\circ}$ ed., 19-53), Brasil: Papirus Editora.

TURISMO DE PORTUGAL, I. P. (2007), Determinação da Representatividade das Motivações Primárias e Estádio de Satisfação dos Turistas em Portugal, Relatório Anual de Pesquisa 2007, Lisboa: IMR -Instituto de Marketing Research.

TURISMO DE PORTUGAL, I. P. (2012), Guia Técnico: Museus e Monumentos.

Viegas, J. (2004), "Implicações Democráticas das Associações Voluntárias: O caso português numa perspectiva comparativa europeia”, Sociologia, Problemas e Práticas, nº 46, (35-50). Lisboa. 
Internet:

www.ine.pt, 2012-07-02

www.wto.org, 2012-10-10

www.avesdeportugal.pt, 2012-11-20

www.cm-fundao.pt, 2013-04-04

www.proder.pt, 2013-04-30 